\title{
Neurological dysfunction of the bladder from myelomeningocele
}

\author{
Dana A. Weiss, MD, ${ }^{1}$ Albert S. Lee, DO, ${ }^{2}$ Tracy M. Flanders, MD, ${ }^{3}$ Christopher J. Long, MD, ${ }^{1}$ \\ Jason P. van Batavia, MD, ${ }^{1}$ Stephen A. Zderic, MD, ${ }^{1}$ and Gregory G. Heuer, MD, PhD ${ }^{4}$

\begin{abstract}
1Division of Urology, Children's Hospital of Philadelphia; ' 2 Department of Urology, Einstein Medical Center, Philadelphia; ${ }^{3}$ Department of Neurosurgery, University of Pennsylvania, Philadelphia; and 'Division of Neurosurgery, Children's Hospital of
\end{abstract} \\ Philadelphia, Pennsylvania
}

\begin{abstract}
Myelomeningocele (MMC) affects approximately 2000 infants in the US yearly and causes long-term damage to the genitourinary system. There is a wide spectrum of effects on the bladder and urethral sphincter that do not correlate with the level of the spinal cord defect. The bladder changes can provide a safe storage pressure, often at the expense of continence, or can create a hostile environment leading to increased pressure on the kidneys and eventually to chronic kidney disease. The ultimate goals in management are to maintain a safe system that prevents renal deterioration, while providing social continence and independence in the long term. This review intends to provide an overview of the effects of MMC on the genitourinary system, regardless of intervention, in order to understand the pathophysiology of the disease.
\end{abstract}

https://thejns.org/doi/abs/10.3171/2019.7.FOCUS19468

KEYWORDS myelomeningocele; neurogenic bladder; tethered cord; neurogenic detrusor overactivity; detrusor external sphincter dyssynergia

$\mathrm{M}$ YELOMENINGOCELE (MMC) occurs in 1 in 1000 live births, with the annual delivery of approximately 2000 infants with this disorder in the US. The effects of open MMC are wide ranging, including neurological, orthopedic, and urological sequelae. ${ }^{20}$ The spectrum of effects on the genitourinary tract are widespread, and the degree of involvement often does not correlate with the level of the spinal cord defect. The majority of the literature regarding neurogenic bladder (NGB) secondary to MMC focuses on optimizing function and minimizing renal deterioration. The management is individualized based on the specific dynamic patterns identified in the bladder, bladder neck, and external urethral sphincter; wide clinical variability also exists among providers. This review is intended to provide an overview of the urological changes seen with MMC regardless of intervention, in order to understand the pathophysiology of the disease and to provide the neurosurgeon and other members of the spina bifida team with a greater understanding of the urological care of the child with MMC.

\section{Innervation and Cellular Changes}

The pelvic and pudendal nerves from S2 to S4 innervate the bladder detrusor muscle and the external urethral sphincter, respectively. ${ }^{6}$ There is no identifiable correlation between type of NGB and sphincteric dysfunction with regard to the bony or functional level of the spinal cord defect in MMC. Therefore, the urological prognosis is nearly impossible to predict at birth.

Although the bladder's gross anatomy is not disrupted, the innervation of the bladder in MMC is abnormal. Shapiro et al. first demonstrated, by staining with S100 for Schwann cells and neurofilament protein for axons in male fetuses with and without MMC at 20 weeks gestation, that fetuses with MMC exhibit decreased peripheral nerve in-

ABBREVIATIONS CIC = clean intermittent self-catheterization; DESD = detrusor external sphincter dyssynergia; DLPP = detrusor leak-point pressure; $\mathrm{DO}=$ detrusor overactivity; $\mathrm{MMC}=$ myelomeningocele; NGB = neurogenic bladder; TCS = tethered cord syndrome; UDS = urodynamic study; UTI = urinary tract infection; VUR = vesicoureteral reflux.

SUBMITTED June 1, 2019. ACCEPTED July 29, 2019.

INCLUDE WHEN CITING DOI: 10.3171/2019.7.FOCUS19468. 
nervation to the bladder, prostate, and rectum compared to controls. ${ }^{47}$

In addition, the parasympathetic pathway has been implicated in NGB. Cholinergic transmitters as well as adenosine 5'-triphosphate (ATP) and neuropeptide Y largely control the efferent neural control of the detrusor. One study found a lower number of neuropeptide $\mathrm{Y}$ nerve fibers in bladders with MMC, supporting the concept of a partial nerve degeneration in the detrusor in NGB. ${ }^{17}$

The distribution of muscle fibers in the bladder has been studied as well. Smooth muscle is scant and less well differentiated in $\mathrm{NGB},{ }^{47}$ with complete disjunction of the muscle cells. ${ }^{16}$ These smooth-muscle cells demonstrate an excess of extracellular matrix deposition, and functionally do not contract properly and are developmentally immature. ${ }^{19}$ Additionally, within the lamina propria and muscularis layers of the bladder wall there is increased fibrosis and this, along with the disarray of muscle cells, can lead to a nonelastic, rigid bladder. ${ }^{6}$ In vitro studies have demonstrated decreased contractility and increased rigidity in muscle strips taken from bladders of patients with MMC. These studies demonstrated that the anticholinergic atropine was less effective in reducing the total contractile force in bladders with MMC than it was in control bladders, and it was also less effective than the sodium channel blocker tetrodotoxin. ${ }^{15}$

For the external urethral sphincter, early fetal studies did not demonstrate any difference in muscle composition between MMC and control tissue samples. ${ }^{47}$ However, a cross-sectional examination of sphincter muscle obtained during sphincterotomy for bladder outlet obstruction showed an increase in fibrous tissue between the smooth and skeletal muscle bundles, whereas no striated muscles were identified in the sphincter from a patient with a complete lower motor neuron lesion. ${ }^{6}$

\section{Functional Changes in NGB}

The neurogenic findings of the bladder can be divided into 3 categories: hyperreflexia or detrusor overactivity (DO), underactive detrusor, and noncontractile detrusor. DO is the most common, occurring in up to $45 \%$ of patients with MMC. ${ }^{16}$ These findings can be accompanied by detrusor external sphincter dyssynergia (DESD), another component of NGB dysfunction. In addition, the bladder neck, which is the internal sphincter of the bladder, can be affected in MMC. The bladder neck may be normal (i.e., competent, remains closed during bladder filling and then opens and funnels during bladder emptying), or it may be continuously open and funneled (incompetent), leading to continuous bladder leakage. The diagnosis of each of these bladder findings is made with a urodynamic study (UDS). The UDS uses a catheter to simultaneously fill the bladder at a fixed rate and to measure pressure. UDSs can be performed in conjunction with fluoroscopic images to correlate the appearance of the bladder and bladder neck with the tracing. UDSs can indicate whether the bladder maintains a low pressure during filling or if it generates increasing pressures with filling, indicating loss of compliance. It also can indicate if there are uninhibited bladder contractions, which are periodic short-duration con- tractions of the detrusor muscle (Fig. 1). Finally, during the UDS, electromyography is performed simultaneously to examine external urethral sphincter activity.

The initial classification of bladder function may be complicated by post-MMC closure sequelae, specifically the development of spinal shock in up to $88 \%$ of patients. This can last anywhere from 2 to 6 weeks. ${ }^{48}$ The final bladder pathology and sphincteric function has never correlated well with the neurological defect, despite longterm follow-up from 2.5 to 15 years of age. ${ }^{6}$ Preservation of sacral innervation is possible even in the setting of more cephalad lesions associated with complete lower-extremity paralysis, whereas conversely, patients with intact lowerextremity function may have complete lack of sacral innervation of the external sphincter. ${ }^{43}$ Moreover, the pattern of sphincteric function may alter over time. Pontari et al. evaluated 151 patients with MMC at L3 or higher, and found that $74 \%$ of patients younger than 1 year of age had sacral nerve-sparing lesions, whereas only $43 \%$ of patients older than 1 year had sacral nerve sparing. ${ }^{43}$ This suggests that sphincteric function can change over time, which further complicates the prognostic understanding of NGB.

Although bladder outcomes do not correlate with the spinal defect level, urethral patterns have been associated with bladder contractility. In a cohort of 207 patients with $\mathrm{MMC}$, in those with contractile bladders, $52 \%$ and $48 \%$ had competent and incompetent bladder necks, respectively, whereas $95 \%$ exhibited DESD. Conversely, in patients with an acontractile bladder, $100 \%$ had incompetent bladder neck and open external urethral sphincters, yet $75 \%$ of this group still demonstrated DESD as well. In the intermediate bladder contractility group, all had an incompetent bladder neck and DESD. ${ }^{39}$ Another study examined bladder contractility with respect to urethral overactivity. In these children with overactive urethral sphincters, $31 / 62(50 \%)$ had DO, whereas the other $50 \%$ had detrusor underactivity or had acontractile bladders. Conversely, in patients with incompetent urethral sphincters, only $3 / 28$ (11\%) had DO, whereas $89 \%$ had underactive or acontractile bladders. ${ }^{51}$ The association between DO and DESD highlights the importance of classifying bladder contractility in order to better understand and stratify for risk the urological outcomes in NGB.

As a corollary to the effects of MMC on the detrusor, bladder neck, and external urethral sphincter, the effect of these components on overall bladder capacity can alter long-term management. The average bladder capacity in patients with NGB before 9 years of age has been found to be $25 \%$ less than that of age-matched controls. ${ }^{40}$ Given that both bladder capacity and compliance are important determinants of ultimate bladder storage pressures and storage ability, which are essential for social continence, it is important to tailor management to optimize both.

Patients with MMC also frequently experience sexual dysfunction; however, this is often not considered by clinicians during routine care, due to the often false assumption that these patients are inherently either asexual or not interested. ${ }^{53}$ Sexual dysfunction in men with spina bifida affects erections and ejaculation. Men can achieve erections but these are often based on sacral reflexes rather than a sexual response, and can occur regardless of neurological 

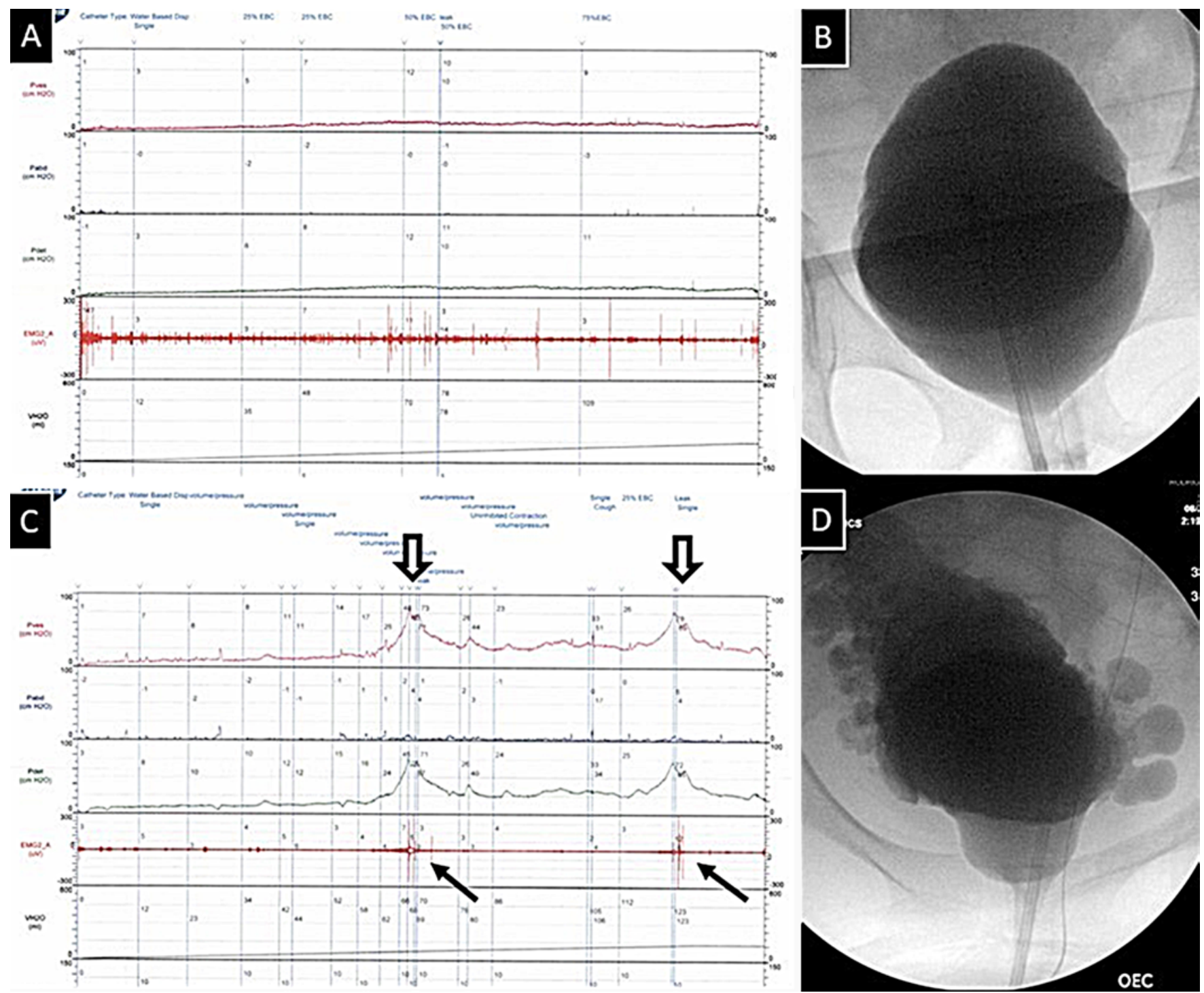

FIG. 1. Video-urodynamic tracings and images. A: Urodynamic tracing of a compliant bladder with detrusor underactivity and no detrusor sphincter dyssynergia. B: Fluoroscopic image taken at maximal filling capacity during a video-urodynamic study demonstrating a smooth-walled bladder with a low-lying, open bladder neck. C: Urodynamic tracing of a poorly compliant bladder with DO. Hollow arrows indicate uninhibited contractions indicative of DO. Solid arrows indicate increased electromyography tone consistent with DESD. D: Fluoroscopic image of a markedly trabeculated bladder.

functional level. Even in patients in whom sacral reflexes are absent, a majority of those with defects below T10 are able to have reflexive erections..$^{53}$ Additionally, there is a sizable minority of men who do report normal erections. One study reported $41 \%$ of males with MMC experience normal erections satisfactory for intercourse, whereas only $18 \%$ report not having any erections. Hydrocephalus and CSF diversion were not found to influence the rate of erectile function, whereas ambulation did: ambulatory patients were considerably more likely to achieve normal erections compared with nonambulatory men. ${ }^{13,44}$ Despite reflexogenic erections, many men may lack penile sensation, due to dysfunction of the pudendal nerve. One study found that in males with defects at L3 or below, approximately $46 \%$ reported decreased or absent genital sensa- tion; in patients with lesions at L2 and above, more than 92\% reported decreased or absent genital sensation. ${ }^{14,24}$ Similarly, the ability to reach orgasm and to ejaculate was shown to occur in 7/9 men with neurological lesions at L3 or below. Although ejaculation can occur in patients with lesions at higher levels, this was not associated with sexual sensation. Ejaculatory dysfunction can be managed with electroejaculation therapy in order to assist reproduction. ${ }^{23}$

Females may also experience sexual dysfunction due to abnormal sensation. Women may demonstrate a different pattern of genital sensation depending on the level of the defect: $3.5 \%$ of females with defects at $\mathrm{S} 1$ or below, $14.3 \%$ of females with defects between L3 and L5, and $44.4 \%$ of females with defects at L2 or above reported decreased or absent genital sensation. ${ }^{23}$ 


\section{Management Strategies}

Early management of NGB was based on continent urinary diversion to manage incontinence and prevent renal deterioration. Before Lapides and colleagues described clean intermittent self-catheterization (CIC) in 1972, ${ }^{30}$ there was no option for emptying the bladder other than Valsalva voiding, crede maneuvers (i.e., manually pushing on the bladder through the abdominal wall), indwelling Foley catheters, or diversion. In the mid-1970s, some clinicians began to question the need for early diversion. A review of 106 patients who underwent MMC closure in the early 1960 s found that $23 \%$ of patients achieved continence without diversion during long-term follow-up. ${ }^{8}$

Starting in the 1970 s, evaluation with a UDS and use of catheterization came into mainstream clinical practice. This facilitated the development of expectant management, in which patients would not receive intervention until the upper urinary tract exhibited concerning findings. The concept of a cutoff number of $40 \mathrm{~cm} \mathrm{H}_{2} \mathrm{O}$ for high-risk detrusor leak-point pressure (DLPP) was introduced by McGuire and associates in $1981 .{ }^{36}$ This number indicated the bladder pressure at which the patient would experience leakage during a UDS. If the bladder would consistently reach pressures greater than $40 \mathrm{~cm} \mathrm{H}_{2} \mathrm{O}$ without leakage, there was found to be increased risk of upper-tract damage such as hydroureteronephrosis, renal scarring, or parenchymal thinning. This number has since guided the management of NGB. In reviewing a cohort of 181 patients, Kaufman and partners found that 79 patients who had been monitored only by serial imaging had developed upper-tract changes. These patients were started on treatment with $\mathrm{CIC}$, with or without anticholinergic medications. Radiographic improvement occurred in 69\% of their patients; however, the majority did not have any improvement in their bladder compliance. Ultimately, 25 patients underwent augmentation and 8 had vesicostomies. $^{27}$

Rather than await upper-tract changes, clinicians began using UDS findings of a high-risk bladder as the cue for intervention. In 1999, Kaefer et al. compared expectant management with early intervention in patients with high-risk UDS findings. Twenty-seven of 45 patients were managed expectantly even in the setting of a high-risk bladder, and intervention was only initiated when uppertract changes were seen on imaging, whereas the other 18 were immediately started on CIC and anticholinergics. In the expectant management cohort, 11/27 (41\%) of patients ultimately underwent augmentation, whereas only $3 / 18$ $(17 \%)$ of those who were started on treatment at the time of diagnosis of high-risk features required augmentation. ${ }^{26}$

Conservative management of the bladder requires patience and close monitoring. It is important to note that there are patients, especially girls, who will achieve continence following puberty, even with no change in intervention. Almodhen et al. followed 26 patients and found that 12 (10 females and 2 males) achieved continence, with an increase in cystometric volume but not in detrusor pressure or DLPP. However, in the 14 patients who did not achieve continence after puberty, UDSs demonstrated an increase in both pressure and DLPP. ${ }^{5}$ Additionally, of 204 newborns with MMC, 25 had abnormal bladders initially, and when followed, $32 \%$ went on to develop deterioration in the first 6 years. The findings of bladder changes triggered MRI studies, which demonstrated retethering of the cord. ${ }^{49}$ However, the bladder can change over time based on growth or natural progression of disease, in the absence of cord retethering. These studies highlight the importance and necessity of ongoing close monitoring of patients with NGB from MMC.

There is still no overarching consensus on the current management of NGB from MMC. In a survey of pediatric urology practitioners, Lodwick et al. found varying patterns in the management of newborn patients with MMC. ${ }^{33}$ Most patients are evaluated with early renal and bladder ultrasound, which is repeated every 6 months for the first 1-2 years, and then annually. Urodynamic evaluation is undertaken after the initial period of spinal shock, usually 2-6 months after closure, and then yearly. High-risk bladder dynamics are treated with a combination of CIC and anticholinergic medications. Occasionally, early vesicostomy is undertaken for very high-risk patients, or urethral dilation for severe DESD. ${ }^{25}$ Figure 2 demonstrates the current algorithm for initial evaluation and management of babies born with spina bifida at our institution.

The Centers for Disease Control and Prevention created a working group in 2012 to develop a protocol for the management of babies with MMC. ${ }^{45}$ This prospective study delineated the early management with CIC until bladder emptying can be ensured, the early use of anticholinergic medications to treat DO, and the use of prophylactic antibiotics. Routine interventions for risk stratification and monitoring of renal function include early serum creatinine measurements, strict criteria for urinary tract infection (UTI) diagnosis, routine renal and bladder ultrasounds, periodic assessment of renal scars with ${ }^{99 \mathrm{~m} T c-}$ dimercaptosuccinic acid (DMSA) renal scan, and routine UDSs. ${ }^{45}$ In this protocol, the UDS places the bladder into 4 categories - "hostile," "intermediate risk," "abnormal but safe," and "normal." Hostility is defined as an end filling pressure or DLPP of $40 \mathrm{~cm} \mathrm{H}_{2} \mathrm{O}$ or more, or the presence of DO and DESD. Conversely, abnormal but safe is defined as having an end filling pressure or DLPP of less than $25 \mathrm{~cm} \mathrm{H}_{2} \mathrm{O}$. Whether this is truly a safe range is yet to be determined.

Beyond the new Centers for Disease Control and Prevention protocol, other adjuncts to the management of NGB include overnight catheter drainage of the bladder to decompress the bladder and kidneys for a prolonged period each day, ${ }^{28}$ the addition of other pharmacological interventions including the beta-3 adrenergic agonist mirabegron for its synergistic effect on the bladder, or injection of botulinum toxin into the detrusor muscle. Finally, for patients in whom all conservative treatments fail, bladder augmentation with intestine may be required, narrowing or closure of the bladder neck may be indicated to create dryness, and catheterizable channels may be created to facilitate bladder emptying.

\section{Fetal Versus Postnatal Closure}

MMC is believed to cause spinal cord injury via a twohit hypothesis: initial injury occurs due to the abnormal 


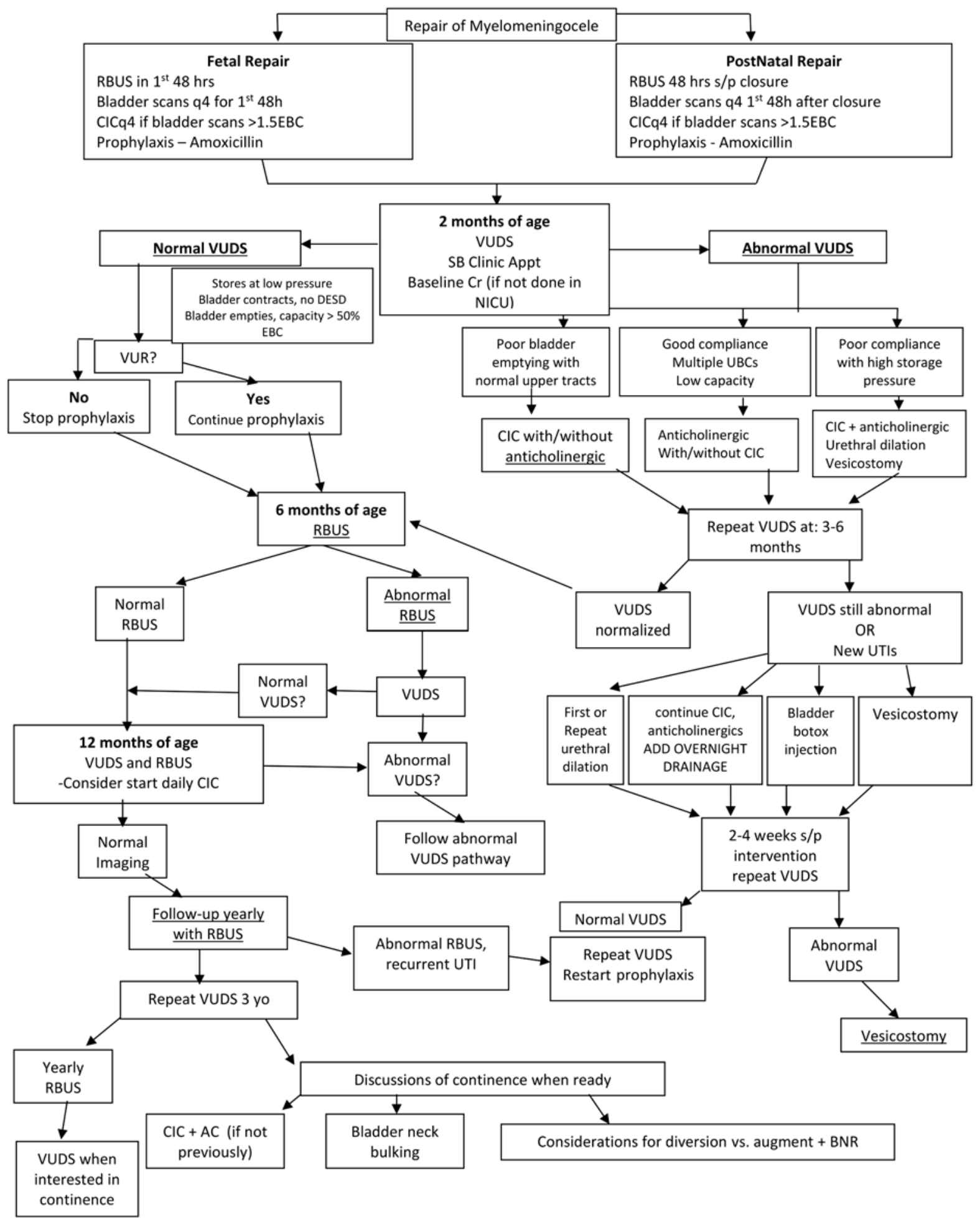

FIG. 2. Current algorithm followed for initial evaluation and management of babies born with spina bifida at our institution. $A C=$ anticholinergic; $\mathrm{Appt}=$ appointment; $\mathrm{BNR}=$ bladder neck reconstruction; $\mathrm{Cr}=$ creatinine; $\mathrm{EBC}=$ expected bladder capacity; NICU = neonatal ICU; $q 4$ = every 4 hours; RBUS = renal bladder ultrasound; SB = spina bifida; $s / p=$ status/post; UBC = uninhibited bladder contractions; VUDS = video-urodynamic study; yo = years old. 
formation and neurulation of the spinal cord itself, and secondary injury develops both due to exposure of spinal nerves to amniotic fluid and to mechanical injury resulting from growth and delivery of the fetus., ${ }^{2,38}$ Several animal studies demonstrated that early in utero closure of the spinal cord defect, to decrease exposure to the amniotic fluid and to provide improved protection against mechanical injuries, resulted in promising reductions of neurological sequelae. 737,46

Since the first successful open fetal MMC repairs in the late 1990s, 3,52 multiple studies have investigated the impact of fetal MMC closures on the long-term neurological function, chief among them the Management of Myelomeningocele Study (MOMS). A randomized controlled trial comparing prenatal and postnatal repair of MMC, the Management of Myelomeningocele Study was terminated early after interim analysis demonstrated significant benefit with fetal MMC closure. The authors found that compared to postnatal closure, those who underwent prenatal closure had significantly decreased need for CSF diversion, decreased hindbrain herniation, improved lower-extremity function, and improved composite score measuring mental development and motor function. ${ }^{4}$ However, subsequent subanalyses of the trial showed prenatal closure did not reduce vesicoureteral reflux (VUR), the need for CIC, or upper-tract dilation. Furthermore, data revealed decreased bladder trabeculation and increased incidence of open bladder neck in girls.9 The authors concluded that the impact of these findings on the long-term function of the bladder was unknown.

Researchers have sought to compare the results of UDSs after prenatal closure with those following postnatal closure. The majority of studies found no significant change in UDS findings when compared to historical postnatal repair controls..$^{11,20,21,31,32,34,41}$ Leal de Cruz et al. found $93.7 \%$ of the 48 patients who had undergone prenatal closure demonstrated high bladder pressure or incontinence. ${ }^{31}$ Macedo et al. found that patients continued to experience negative urological sequelae of MMC after prenatal closure: approximately one-third continued to have hydronephrosis, approximately one-quarter demonstrated VUR, and approximately one-half experienced pyelonephritis. ${ }^{34}$ However, these findings were not universal. A small prospective study comparing 8 patients who underwent prenatal closure to 8 patients who underwent postnatal closure demonstrated that fetal closure resulted in higher rates of normal bladder function ( $100 \%$ vs $50 \%$ ), decreased incidence of febrile UTIs (37.5\% vs $62.5 \%$ ), and less bladder wall thickening $(37.5 \%$ vs $87.5 \%) .22$

Studies have investigated the impact of prenatal MMC closure on continence. Koh et al. found that prenatal closure was associated with a higher incidence of complete denervation of the external urethral sphincter; the authors hypothesized that these patients would be at higher risk for incontinence and upper-tract damage. ${ }^{29}$ However, studies by Pastuszka et al. and Carr showed that those who underwent fetal repair had improved continence, with Pastuszka showing that patients undergoing prenatal closure had an $81 \%$ chance of social dryness after the third year of life compared to $70 \%$ incontinence in those who underwent closure postnatally. ${ }^{41}$ Similarly, Carr showed a higher rate of successful toilet training after prenatal MMC closure $(18.5 \%$ vs $8.3 \%) . .^{10}$

Current evidence suggests that patients with prenatal MMC closure potentially have a higher chance of achieving continence, but still require close monitoring of their bladder function and upper urinary tract because their UDS did not show any significant change when compared to those who undergo postnatal closure.

\section{Tethered Cord Syndrome}

After initial closure of MMC, a retethering of the cord can occur. The tethered cord results from fixation of the spinal cord by scarring, which leads to ischemia, mitochondrial anoxia, and progressive neural deterioration. ${ }^{12}$ The effects on the bladder of tethered cord syndrome (TCS) have been evaluated both for prenatal and postnatal closures. Ultimately, there is a range of $13 \%-80 \%$ improvement in urinary symptoms after detethering. ${ }^{12,18,35}$

A study of 401 children with postnatal closure found that $56(14 \%)$ had secondary tethering. ${ }^{50}$ Fifty-nine percent were diagnosed due to new urological problems, with new urinary tract dilation in $11(20 \%)$, VUR in $17(30 \%)$, and findings of decreased compliance, increases in DLPP, recurrent UTIs, or worsening incontinence. After treatment of this secondary tethering, bladder capacity and DLPP improved within 6 months. This study found that age at the time of treatment did affect the improvement seen on the UDS, with better outcomes seen in patients with detethering prior to 7 years of age..$^{50}$

Conservative management of TCS has been attempted, but there can be progressive effects over the long term, so treatment is recommended. ${ }^{42}$ Given that early intervention may improve outcomes in TCS, routine UDS evaluation is critical because it may demonstrate subtle findings that can portend more symptomatic and obvious findings that would develop later. ${ }^{18}$

Preoperative findings of suspected secondary retethering include increased weakness $(55 \%)$, worsening gait (54\%), scoliosis (51\%), pain (32\%), orthopedic deformity (11\%), and urological dysfunction (6\%). ${ }^{1}$ Among urological dysfunctions, DO is the most common, occurring in $88.7 \%$ of both patients with MMC and those with spinal lipoma. Worsened incontinence was found in only $9.4 \%$ of these patients. ${ }^{18}$ In a study of complex cord detethering, $80 \%$ of patients with incontinence and $75 \%$ of patients with DO improved. Moreover, there was an increase in cystometric capacity on UDSs, whereas only 3 patients had worsened urinary symptoms. ${ }^{18}$

In a group of 20 patients from Sweden undergoing detethering surgery, 6 had experienced deterioration in UDS findings prior to detethering. After surgery, all 6 improved to a milder form of bladder dysfunction, as did 1 patient who had not experienced worsening prior to surgery, for a total of 7/20 (35\%) improved. One patient deteriorated from mild to moderate dysfunction after detethering. ${ }^{1}$

In another study of patients undergoing multiple procedures to treat retethering, an evaluation before the third detethering showed incontinence in 7/13 (53\%), and 5 of these had symptomatic improvement postoperatively. There were 7 others who had no symptoms prior to de- 
tethering, and who had worsened incontinence after detethering. ${ }^{35}$ On objective postoperative assessment of the urethral sphincter, those with an "improved" sphincter had a decrease in continence, whereas those with a "worsened" sphincter had improved continence.

\section{Conclusions}

MMC affects the bladder regardless of the level of the defect or the timing of closure. The management of the resulting NGB must be individualized based on the pattern of injury, and must be routinely evaluated because the dynamics of the bladder can change over time. Appropriate counseling of parents includes discussion of the long-term urological care that will be required in order to prevent upper-tract deterioration and provide for long-term social continence and eventually independence.

\section{References}

1. Abrahamsson K, Olsson I, Sillén U: Urodynamic findings in children with myelomeningocele after untethering of the spinal cord. J Urol 177:331-334, 2007

2. Adzick NS: Fetal myelomeningocele: natural history, pathophysiology, and in-utero intervention. Semin Fetal Neonatal Med 15:9-14, 2010

3. Adzick NS, Sutton LN, Crombleholme TM, Flake AW: Successful fetal surgery for spina bifida. Lancet 352:1675-1676, 1998

4. Adzick NS, Thom EA, Spong CY, Brock JW III, Burrows PK, Johnson MP, et al: A randomized trial of prenatal versus postnatal repair of myelomeningocele. N Engl J Med 364:993-1004, 2011

5. Almodhen F, Capolicchio JP, Jednak R, El Sherbiny M: Postpubertal urodynamic and upper urinary tract changes in children with conservatively treated myelomeningocele. J Urol 178:1479-1482, 2007

6. Bauer SB, Labib KB, Dieppa RA, Retik AB: Urodynamic evaluation of boy with myelodysplasia and incontinence. Urology 10:354-362, 1977

7. Bouchard S, Davey MG, Rintoul NE, Walsh DS, Rorke LB, Adzick NS: Correction of hindbrain herniation and anatomy of the vermis after in utero repair of myelomeningocele in sheep. J Pediatr Surg 38:451-458, 2003

8. Brereton RJ, Zachary RB, Lister J: Urinary continence in open myelomeningocele. Arch Dis Child 52:703-707, 1977

9. Brock JW III, Carr MC, Adzick NS, Burrows PK, Thomas JC, Thom EA, et al: Bladder function after fetal surgery for myelomeningocele. Pediatrics 136:e906-e913, 2015

10. Carr MC: Urological results after fetal myelomeningocele repair in pre-MOMS trial patients at the Children's Hospital of Philadelphia. Fetal Diagn Ther 37:211-218, 2015

11. Clayton DB, Tanaka ST, Trusler L, Thomas JC, Pope JC IV, Adams MC, et al: Long-term urological impact of fetal myelomeningocele closure. J Urol 186 (4 Suppl):1581-1585, 2011

12. Danzer E, Adzick NS, Rintoul NE, Zarnow DM, Schwartz ES, Melchionni J, et al: Intradural inclusion cysts following in utero closure of myelomeningocele: clinical implications and follow-up findings. J Neurosurg Pediatr 2:406-413, 2008

13. Decter RM, Furness PD III, Nguyen TA, McGowan M, Laudermilch C, Telenko A: Reproductive understanding, sexual functioning and testosterone levels in men with spina bifida. J Urol 157:1466-1468, 1997

14. Gatti C, Del Rossi C, Ferrari A, Casolari E, Casadio G, Scire G: Predictors of successful sexual partnering of adults with spina bifida. J Urol 182 (4 Suppl):1911-1916, 2009
15. Ghoniem GM, Shoukry MS, Hassouna ME: Detrusor properties in myelomeningocele patients: in vitro study. J Urol 159:2193-2196, 1998

16. Haferkamp A, Dörsam J, Resnick NM, Yalla SV, Elbadawi A: Structural basis of neurogenic bladder dysfunction. II. Myogenic basis of detrusor hyperreflexia. J Urol 169:547554,2003

17. Haferkamp A, Freund T, Wagener N, Reitz A, Schurch B, Doersam J, et al: Distribution of neuropeptide Y-containing nerves in the neurogenic and non-neurogenic detrusor. BJU Int 97:393-399, 2006

18. Hayashi T, Takemoto J, Ochiai T, Kimiwada T, Shirane R, Sakai K, et al: Surgical indication and outcome in patients with postoperative retethered cord syndrome. J Neurosurg Pediatr 11:133-139, 2013

19. Hipp JA, Hipp JD, Yoo JJ, Atala A, Andersson KE: Microarray analysis of bladder smooth muscle from patients with myelomeningocele. BJU Int 102:741-746, 2008

20. Holmes NM, Nguyen HT, Harrison MR, Farmer DL, Baskin LS: Fetal intervention for myelomeningocele: effect on postnatal bladder function. J Urol 166:2383-2386, 2001

21. Holzbeierlein J, Pope JC IV, Adams MC, Bruner J, Tulipan N, Brock JW III: The urodynamic profile of myelodysplasia in childhood with spinal closure during gestation. J Urol 164:1336-1339, 2000

22. Horst M, Mazzone L, Schraner T, Bodmer C, Möhrlen U, Meuli M, et al: Prenatal myelomeningocele repair: do bladders better? Neurourol Urodyn 36:1651-1658, 2017

23. Hsieh MH, Hollander A, Lamb DJ, Turek PJ: The genetic and phenotypic basis of infertility in men with pediatric urologic disorders. Urology 76:25-31, 2010

24. Jacobs MA, Avellino AM, Shurtleff D, Lendvay TS: Reinnervating the penis in spina bifida patients in the United States: ilioinguinal-to-dorsal-penile neurorrhaphy in two cases. J Sex Med 10:2593-2597, 2013

25. Jayanthi VR, McLorie GA, Khoury AE, Churchill BM: The effect of temporary cutaneous diversion on ultimate bladder function. J Urol 154:889-892, 1995

26. Kaefer M, Pabby A, Kelly M, Darbey M, Bauer SB: Improved bladder function after prophylactic treatment of the high risk neurogenic bladder in newborns with myelomentingocele. J Urol 162:1068-1071, 1999

27. Kaufman AM, Ritchey ML, Roberts AC, Rudy DC, McGuire EJ: Decreased bladder compliance in patients with myelomeningocele treated with radiological observation. J Urol 156:2031-2033, 1996

28. Koff SA, Gigax MR, Jayanthi VR: Nocturnal bladder emptying: a simple technique for reversing urinary tract deterioration in children with neurogenic bladder. J Urol 174:16291632,2005

29. Koh CJ, DeFilippo RE, Borer JG, Khoshbin S, Bauer SB: Bladder and external urethral sphincter function after prenatal closure of myelomeningocele. J Urol 176:2232-2236, 2006

30. Lapides J, Diokno AC, Silber SJ, Lowe BS: Clean, intermittent self-catheterization in the treatment of urinary tract disease. J Urol 107:458-461, 1972

31. Leal da Cruz M, Liguori R, Garrone G, Leslie B, Ottoni SL, Carvalheiro $\mathrm{S}$, et al: Categorization of bladder dynamics and treatment after fetal myelomeningocele repair: first 50 cases prospectively assessed. J Urol 193 (5 Suppl):1808-1811, 2015

32. Lee NG, Gomez P, Uberoi V, Kokorowski PJ, Khoshbin S, Bauer SB, et al: In utero closure of myelomeningocele does not improve lower urinary tract function. J Urol 188 (4 Suppl):1567-1571, 2012

33. Lodwick D, Asti L, Deans K, Minneci P, McLeod D: Variation in practice patterns for the management of newborn spina bifida in the United States. Urology 100:207-212, 2017 
34. Macedo A Jr, Leal M, Rondon A, Ortiz V, Moron AF, Cavalheiro S: Urological evaluation of patients that had undergone in utero myelomeningocele closure: A prospective assessment at first presentation and early follow-up. Do their bladder benefit from it? Neurourol Urodyn 34:461-464, 2015

35. Maher CO, Bauer SB, Goumnerova L, Proctor MR, Madsen JR, Scott RM: Urological outcome following multiple repeat spinal cord untethering operations. Clinical article. J Neurosurg Pediatr 4:275-279, 2009

36. McGuire EJ, Woodside JR, Borden TA, Weiss RM: Prognostic value of urodynamic testing in myelodysplastic patients. J Urol 126:205-209, 1981

37. Meuli M, Meuli-Simmen C, Hutchins GM, Yingling CD, Hoffman KM, Harrison MR, et al: In utero surgery rescues neurological function at birth in sheep with spina bifida. Nat Med 1:342-347, 1995

38. Meuli M, Moehrlen U: Fetal surgery for myelomeningocele: a critical appraisal. Eur J Pediatr Surg 23:103-109, 2013

39. Mundy AR, Shah PJR, Borzyskowski M, Saxton HM: Sphincter behaviour in myelomeningocele. Br J Urol 57:647-651, 1985

40. Palmer LS, Richards I, Kaplan WE: Age related bladder capacity and bladder capacity growth in children with myelomeningocele. J Urol 158:1261-1264, 1997

41. Pastuszka A, Bohosiewicz J, Koszutski T: Prenatal myelomeningocele repair improves urinary continence and reduces the risk of constipation. Neurourol Urodyn 37:2792-2798, 2018

42. Phuong LK, Schoeberl KA, Raffel C, Sutton LN, Humphreys RP, McComb JG, et al: Natural history of tethered cord in patients with meningomyelocele. Neurosurgery 50:989-995, 2002

43. Pontari MA, Keating M, Kelly M, Dyro F, Bauer SB: Retained sacral function in children with high level myelodysplasia. J Urol 154:775-777, 1995

44. Roth JD, Misseri R, Cain MP, Szymanski KM: Mobility, hydrocephalus and quality of erections in men with spina bifida. J Pediatr Urol 13:264.e1-264.e6, 2017

45. Routh JC, Cheng EY, Austin JC, Baum MA, Gargollo PC, Grady RW, et al: Design and methodological considerations for the Centers for Disease Control and Prevention urologic and renal protocol for the newborn and young child with spina bifida. J Urol 196:1728-1734, 2016

46. Selçuki M, Manning S, Bernfield M: The curly tail mouse model of human neural tube defects demonstrates normal spinal cord differentiation at the level of the meningomyelocele: implications for fetal surgery. Childs Nerv Syst 17:19-23, 2001
47. Shapiro E, Seller MJ, Lepor H, Kalousek DK, Hutchins GM, Perlman EJ, et al: Altered smooth muscle development and innervation in the lower genitourinary and gastrointestinal tract of the male human fetus with myelomeningocele. J Urol 160:1047-1053, 1079, 1998

48. Stoneking BJ, Brock JW, Pope JC, Adams MC: Early evolution of bladder emptying after myelomeningocele closure. Urology 58:767-771, 2001

49. Tarcan T, Bauer S, Olmedo E, Khoshbin S, Kelly M, Darbey M: Long-term followup of newborns with myelodysplasia and normal urodynamic findings: Is followup necessary? J Urol 165:564-567, 2001

50. Tarcan T, Önol FF, Ilker Y, Simsek F, Ozek M: Does surgical release of secondary spinal cord tethering improve the prognosis of neurogenic bladder in children with myelomeningocele? J Urol 176:1601-1606, 2006 (Erratum in J Urol 176:2749, 2006)

51. Thorup J, Biering-Sorensen F, Cortes D: Urological outcome after myelomeningocele: 20 years of follow-up. BJU Int 107:994-999, 2011

52. Tulipan N, Bruner JP: Myelomeningocele repair in utero: a report of three cases. Pediatr Neurosurg 28:177-180, 1998

53. Woodhouse CRJ: Sexual function in boys born with exstrophy, myelomeningocele, and micropenis. Urology 52:3-11, 1998

\section{Disclosures}

The authors report no conflict of interest concerning the materials or methods used in this study or the findings specified in this paper.

\section{Author Contributions}

Conception and design: Weiss, Heuer. Drafting the article: Weiss, Lee. Critically revising the article: Lee, Flanders, Long, van Batavia, Zderic, Heuer. Reviewed submitted version of manuscript: all authors. Approved the final version of the manuscript on behalf of all authors: Weiss. Administrative/ technical/material support: Weiss.

\section{Correspondence}

Dana A. Weiss: Children's Hospital of Philadelphia, PA. weissd1@email.chop.edu. 